\title{
The role of medical personnel and the environment in the transmission of healthcare-associated infections in the paediatric unit of a University Teaching Hospital
}

\author{
Catherine Kesah FUSI NGWA ${ }^{1^{*}}$, Mathias EGRI- OKWAJI ${ }^{2}$ and Tolu ODUGBEMI ${ }^{3}$ \\ ${ }^{1}$ Department of Animal Biology, Faculty of Science, University of Dschang, P.O box 67, Dschang, West \\ Region, Cameroon. \\ ${ }^{2}$ Department of Paediatrics, Lagos University Teaching Hospital, P.M.B. 12003, Lagos, Nigeria. \\ ${ }^{3}$ Department of Medical Microbiology and Parasitology, College of Medicine, University of Lagos, P.M.B. \\ 12003 Lagos, Nigeria. \\ ${ }^{*}$ Corresponding author, E-mail: fncathkesah@yahoo.com
}

\begin{abstract}
Medical personnel, the environment and devices in paediatric wards at the Lagos University Teaching Hospital (LUTH) were screened to identify possible reservoirs/routes of spread of infections and to evaluate the effectiveness of decontamination processes. Between April and June 1995, nasal, throat and hand swabs as well as urine, stool and swabs of staff uniforms were collected from 126 personnel. Equipment, surfaces, soap, disinfectants, sterile instruments, dressings and the air were also sampled. Further, a questionnaire was administered to assess the general healthcare situation as viewed by staff. All specimens were processed according to standard techniques. Staphylococcus aureus isolated from nasal swabs was tested to Methicillin by Oxacillin E test. Only 74 (59\%) hand swabs were sterile, whereas $52(41 \%)$ had pure and/or mixed growth of staphylococci, enterococci, Bacillus and gram-negative bacteria. Sixty-six (52\%) staff were nasal carriers of

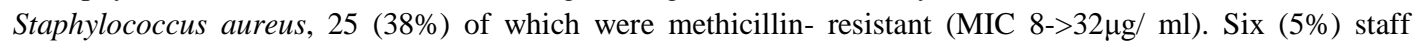
harboured Streptococcus pyogenes in throat swabs, 2 (8\%) Escherichia coli in faecal specimens and 9 (11\%) had significant bacteriuria. Most frequently used equipment/materials were recontaminated within the 12 hours of sampling. Some disinfectants were contaminated by gram- negative bacteria. Understaffing, overcrowding and insufficient equipment reportedly militated against adequate patient care. These findings highlight the necessity for hospitals to ensure thorough personal, environmental and professional asepsis through implementation of appropriate guidelines or measures suggested herein.
\end{abstract}

(C) 2010 International Formulae Group. All rights reserved.

Keywords: Nosocomial infections, reservoirs, staff, the healthcare environment, Paediatrics, surveillance.

\section{INTRODUCTION}

Infection control in paediatrics remains a focus in the healthcare delivery system. As part of normal development, children interact closely with caregivers, family members (parents, siblings), friends, healthcare workers and their environment. This level of contact results in a potentially greater risk of transmission of both healthcare-associated and community pathogens. Sometimes, certain social and/or cultural norms pose infection risk (Jellife and Stanfield, 1982), thus, in some hospitals, visitors are educated via leaflets, posters and healthcare workers in 
order to ensure that they don't transmit pathogens to children or contaminate the hospital environment. Environmental transmission of pathogens involves contaminated work surfaces, floors and medical equipment among others (Montgomery et al., 2010; Muller and Detsky, 2010; Gould et al., 2010; Graham, 2010; Rossini et al., 2010; Stanforth et al., 2010). More still, carriage of potential pathogens by medical personnel, caretakers and visitors, and slips in infection practices particularly hand washing, sterilization, disinfection or asepsis may also pose risks of healthcare-associated infections (HCAIs). Toys and animals form an indispensable component of the environment for hospitalized children but they undisputedly have the potential to transmit infections.

In healthcare delivery, certain personal characteristics and exposures determine a patient's predisposition to or risk of becoming infected. The aetiology of HCAIs might be endogenous or exogenous. Intrinsic risk factors are those that are inherent in the patient because of the underlying disease conditions, while extrinsic risk factors may reside in the patient care staff ( practices of an individual medical personnel) or the institution (practices in an entire hospital) (Maki, 1978; Pechere, 1993; Fujita, 1994).

HCAIs have been associated with inadequate attention being given to, vehicles of infection, conditions which favour crosscontamination, and the inappropriate use of antiseptics/disinfectants in hospitals (Herwaldt and Wenzel, 1995; Kaltenthaler and Pinfold, 1995; French et al., 1996). Generally, nonadherence to regular preventive measures and insanitary conditions are known to influence sporadic or epidemic infections (Boyce et al., 1994; Federal Register notice, 1994; Mulhausen et al., 1996).

In modern hospitals, the major reservoirs of common hospital pathogens are healthcare personnel, patients and visitors (Mulhausen et al., 1996). Body sites that are frequently colonized by pathogens include the nares, the skin, and the gastrointestinal and genitourinary tracts. The environment is a less common reservoir for infections (Boyce et al., 1994). Colonized or infected patients/staff can contaminate the environment with pathogens and this can then serve as sources of cross infections for others i.e. secondary reservoirs (Dismuke, 1996). Furthermore, the environment can serve as the primary reservoir for other organisms, and such reservoirs include water and food (Hooper, 1971; Wright et al., 1976; Anyiwo et al., 1982; Helms et al., 1988). From the reservoirs, nosocomial pathogens are transmitted via five main routes namely contact, droplet, common vehicle, airborne and vector borne transmission. The most important and frequent mode of transmission is through contact (staff to patient and/or vice versa, patient to patient and inanimate objects to patient/staff), and hands of staff have been most implicated (Casewell and Philips, 1977; Samore et al., 1996).

It has been observed that bacterial pathogens are the most common in hospital environments (Herwaldt and Wenzel, 1995). Children because of their low level of resistance to infections are a vulnerable group. In low income countries such as Nigeria, children are more exposed to poor hygienic habits. In this wise, frequent cleaning of patient care items, bedside equipment and frequently touched surfaces is necessary particularly when incessant strikes propound insanity (Federal Register notice, 1994). Periodic screening of staff and adequate environmental control are therefore crucial especially in the newborn and critical care patient units in order to minimize the risk of infection, and perhaps reverse the upward trend in hospital epidemics.

The objective of this study was to identify possible routes of spread of infections through screening of medical staff and the environment in the Paediatric Department of the Lagos University Teaching Hospital (LUTH). This exercise also sought to evaluate 
the effectiveness of various decontamination processes-cleaning, disinfection and sterilization. This was for the purpose of better assessing and remedying the health situation in Paediatric wards. The results of this study were also intended to help infection control practitioners at LUTH and similar centres elsewhere to develop more effective control measures and more rational guidelines for decontamination and microbiologic surveillance of the hospital environment.

\section{MATERIALS AND METHODS} Screening of medical personnel

This study, which was carried out between April and June of 1995, involved doctors and nurses in the various paediatric wards at LUTH viz the out born intensive care unit (ICU)- DI, the in born ICU- NNU, the lying-in wards- $\mathrm{C} 2 / \mathrm{C} 3$, the general Paediatric wards-D2/D3, the paediatric surgical wardE4 and the theatre. Nasal, throat and hand swabs as well as urine and stool specimens were collected from 126 medical personnel46 doctors, 80 nurses (Table 1). Sterile swab sticks moistened in sterile normal saline were used to obtain nasal and hand swabs. Hands of staff were swabbed after washing with nonmedicated soap and dried with electric dryers as a prerequisite for patient care. Urine and stool were collected in sterile universal containers. Staff uniforms were also swabbed using sterile swab sticks moistened in sterile distilled water. Specimens were collected from medical staff only once.

\section{Environmental sampling}

Environmental screening was performed over a three-month period (AprilJune, 1995). Samples were collected three times a week (i.e. on Monday, Wednesday and Friday)

\section{Equipment and surfaces}

The equipment and surfaces included cot/ bed rails, weighing scales, incubators, oxygen tubes, ambubags, laryngoscopes, endoscopes, suction catheters, nasal/oral endotracheal tubes, theatre light, ceiling above theatre light, face masks, dressing trolley tops, locker tops, furniture surfaces, table surfaces/areas for feed preparation, wash basins, bedpans, toilet seats and handles, sluice areas, taps, floors, walls and furniture. These were observed over a period of 12 hours. At the initial stage, the surfaces were swabbed prior to and 5 minutes after cleaning. Swabbing continued on a four- hourly basis for 12 hours to determine the magnitude of recontamination. The effectiveness of decontamination of equipment/surfaces was expressed as below, compared with the initial inoculum of the particular surface:

$4+-$ no growth (100\% reduction)

$3+-75 \%$ reduction

$2+-50 \%$ reduction

$1+-25 \%$ reduction

- $\quad$ - no reduction

In addition, soap and disinfectant solutions provided in the various wards and theatre were examined once every week.

\section{Air sampling}

The air in the various wards and theatre was sampled by exposing settle plates. Two sets of MacConkey and blood agar plates were exposed for one hour and 24 hours in each ward and the theatre. Exposed plates were further incubated in air at $37{ }^{\circ} \mathrm{C}$ for 24 and 48 hours. Contamination of the air was expressed as the number of colonies for the period of exposure.

\section{Sterile instruments and dressings}

Sterile instruments and dressings ready to be used on patients were screened. Portions of dressings for culture were cut off using sterile scissors and forceps. Other sterile instruments were swabbed.

\section{Administration of questionnaire in the Paediatric Department}

A questionnaire was further drawn up to assess the general healthcare situation in the 
Department as seen by the medical personnel. Information contained in the questionnaire included common diseases and HCAIs diagnosed in the various paediatric wards, the possible sources of such infections and possible remedies. Data were also obtained on hand hygiene, its frequency and necessity, and how knowledgeable staff was on this very important aspect of care. Other data were collected on factors which limit staff performance and what suggestions they could advance to help better the health situation in the wards.

\section{Processing of samples}

All samples collected were processed according to standard techniques (Stokes and Ridgway, 1980). Urine specimens were cultured on MacConkey agar and blood agar and incubated in air at $37{ }^{\circ} \mathrm{C}$ for $18-24$ hours. Stool was initially inoculated onto MacConkey agar and Deoxycholate Citrate agar and incubated aerobically at $37^{\circ} \mathrm{C}$ for 18 24 hours. Furthermore, three loopfuls of faecal material were inoculated into Selenite F broth, alkaline peptone water and phosphatebuffered saline. Incubation and subinoculation onto relevant selective media were carried out under appropriate conditions (Murray et al., 1995).

Culture of throat swabs was performed on sheep blood and chocolate agar plates, and incubated at $37^{\circ} \mathrm{C}$ in a candle extinction jar. All other swab samples were inoculated onto MacConkey agar and sheep blood agar, and incubation was done in air at $37^{\circ} \mathrm{C}$.

Brain Heart Infusion (BHI) and cooked meat broth media were used in culturing dressings. The inoculated broth media were incubated in air at $37{ }^{\circ} \mathrm{C}$ for 7 days, subinoculations being made when necessary. More still, $2 \mathrm{ml}$ of each disinfectant/antiseptic solution were inoculated into $18 \mathrm{ml}$ of double strength BHI broth.

All organisms isolated from the various surfaces were identified as recommended (Murray et al., 1995). Identification of gram- negative bacilli was by the use of API $20 \mathrm{E}$ AND API 20 NE (Analytic Profile Index System, BioMerieux 69280 Marcy L'Etoile, France).

Staphylococcus aureus strains isolated from nasal swabs of staff were tested to methicilin by oxacillin E test (AB Biodisk, Sweden) on Mueller- Hinton agar (Oxoid) containing $2 \%$ sodium chloride. The sensitivity agar plates were incubated at $37{ }^{\circ} \mathrm{C}$ (presently recommended at $30{ }^{\circ} \mathrm{C}$ ) for 24 hours, and the results interpreted as recommended (NCCLS, 1993 now CLSI, 2010). S. aureus ATCC 29213 was also tested.

\section{Problems encountered}

A total coverage of all paediatric medical staff was anticipated, but due to inaccessibility of some of the members of staff, only 126 responded. Quantitative air analysis could not be performed due to unavailability of an air sampler (the air sample in the Microbiology Department at the College of Medicine of the University of Lagos had broken down). Due to limited resources, water and food could not be examined.

\section{RESULTS}

Seventy-four $(59 \%)$ of the staff did not have growth on the hands after washing and drying ready to work on patients. Of the 52 (41\%) hand swabs with growth, 19 (15\%) had growth of coagulase-negative staphylococci (CNS) only, twelve (10\%) of the staff had mixed growth of CNS and Enterococcus faecalis, $8(6 \%)$ had Klebsiella pneumoniae and CNS, and 7 (6\%) grew E. faecalis and Bacillus spp. Escherichia coli and CNS (3\%), and Enterobacter cloacae and $E$ feacalis $(12 \%)$ were least isolated (Table 2).

S. aureus was isolated from the noses of 66 of the staff screened, giving an alarming carrier rate of $52 \%$. Twenty-five $(38 \%)$ of the 66 isolates of $S$. aureus were resistant to methicillin, with minimum inhibitory 
concentrations (MICs) ranging between 8 and $>32 \mu \mathrm{g} / \mathrm{ml}$. The highest proportion $(21 \%)$ of nasal carries of this organism occurred in the paediatric surgical ward E4 and the least in theatre staff (3\%). K. pneumoniae was isolated in association with $S$. aureus from 5 (4\%) members of staff, and occurred singly in $11(9 \%)$ of them. Other organisms isolated from nasal swabs included CNS from 29 (23\%) and E. faecalis 20 (16\%) staff (Table 3).

Streptococcus pyogenes was isolated from $6(5 \%)$ throat swabs of staff who complained of respiratory tract infections. Significant bacteriuria was observed in 9 (11\%) staff, $6(66.7 \%)$ of whom were symptomatic. Organisms isolated from the urine samples were $K$. pneumoniae (5). E. coli (2), Citrobacter freundii (1) and S. aureus (1). E. coli was culture from $2(8 \%)$ stool samples but was not typed due to unavailability of antisera. S. aureus, CNS, Enterococci and species of Bacillus Enterobacter, Klebsiella and Acinetobacter, as well as fungi were isolated from staff clothing.

Table 4 summarizes the percentages (mean values obtained over the 3-month period) of reduction in the microbial flora of various surfaces cleaned/disinfected and screened over a 12-hour period. Generally, a $75-100 \%$ reduction in flora was observed after 5 minutes for most equipment screenedincubators, oxygen tubes, weighing scales, rails, ambubags, laryngoscopes, endoscopes, endotracheal tubes and dressing trolley tops. This percentage range in microbial reduction remained fairly stable despite the use of this equipment over the 12-hours observation period. On the contrary, $25-75 \%$ microbial reduction was observed after 5 minutes for some surfaces notably toilet seats, sluice areas, taps, sinks, floors, bedpans, wash basins and surfaces for feed preparation. In the ensuing 12 hours, there was a substantial increment in the flora of these "busy surfaces" (surfaces in use). Recontamination was quite rapid, up to the point of "no reduction" (organisms' counts restored to or even exceeding initial counts before decontamination) in about $50 \%$ of such surfaces at the $12^{\text {th }}$ hour. In NNU where decontamination of surfaces was done twice daily, levels of recontamination were very minimal throughout the 12-hour period of survey. The flora of equipment/surfaces examined comprised staphylococci, enterococci, Bacillus spp, fungi, Clostridium spp., and enteric and non-enteric gramnegative bacilli.

Six different samples of disinfectant solutions obtained from wards D1/D3, NNU and E4 were found to be contaminated by Chryseomonas luteola, Flavimonas oryzihabitans, Pseudomonas aeruginosa, Pseudomonas spp. Proteus mirabilis and $K$. pneumoniae. A cinetobacter and Bacillus spp were isolated from washing soap in ward D1. All sterile instruments and dressings screened had no growth. In the air analysis, colony counts ranged between 50 and 200 colony forming units (CFUs) when plates exposed for an hour in the wards/ theatre were further incubated at $37^{\circ} \mathrm{C}$ for 24 hours. Exposure of plates for 24 hours gave counts of 36-120 CFUs. Growth on these plates was however, semi confluent/ confluent when the incubation period was extended to 48 hours in the laboratory. Different organisms cultured from the air included mainly $S$. aureus, CNS, enterococci, Bacillus spp. and fungi. Gram negative organisms identified in relatively smaller numbers were Klebsiella spp., Enterobacter agglomerans, Flav. oryzihabitans and Acinetobacter spp.

According to the responses from the questionnaires administered, medical staff reported some hindrances to their smooth functioning such as understaffing, overcrowding, and inadequate supply of materials such as syringes, needles, sterile instruments, dressing packs, sterile universal containers, swab sticks and equipment for patient care. 
C. K. FUSI NGWA et al. / Int. J. Biol. Chem. Sci. 4(5): 1529-1542, 2010

Table 1: Ward distribution of paediatric medical staff screened and specimens collected.

\begin{tabular}{|c|c|c|c|c|c|c|c|c|}
\hline Wards & Doctors & Nurses & Total & Hand swabs & Nasal swabs & Throat swabs & Urine & Stool \\
\hline D1 & 10 & 11 & 21 & 21 & 21 & 21 & 18 & 7 \\
\hline NNU & 9 & 10 & 19 & 19 & 19 & 19 & 12 & 8 \\
\hline $\mathrm{C} 2$ & 2 & 8 & 10 & 10 & 10 & 10 & 3 & 1 \\
\hline $\mathrm{C} 3$ & 3 & 6 & 9 & 9 & 9 & 9 & 4 & 1 \\
\hline D2 & 5 & 12 & 17 & 17 & 17 & 17 & 10 & - \\
\hline D3 & 4 & 14 & 18 & 18 & 18 & 18 & 14 & 5 \\
\hline E4 & 7 & 15 & 22 & 22 & 22 & 22 & 19 & 4 \\
\hline Theatre & 6 & 4 & 10 & 10 & 10 & 10 & - & - \\
\hline Total & 46 & 80 & 126 & 126 & 126 & 126 & 80 & 26 \\
\hline
\end{tabular}




\section{K. FUSI NGWA et al. / Int. J. Biol. Chem. Sci. 4(5): 1529-1542, 2010}

Table 2: Distribution of organisms isolated from hand cultures of paediatric medical staff.

\begin{tabular}{|c|c|c|c|c|c|c|c|c|c|}
\hline \multirow[t]{2}{*}{ WARDS } & \multicolumn{9}{|c|}{ No. of organisms isolated } \\
\hline & $\begin{array}{l}\text { No. hand } \\
\text { cultures } \\
\text { screened }\end{array}$ & $\begin{array}{l}\text { No. \% } \\
\text { sterile }\end{array}$ & $\begin{array}{c}\text { No. }(\%) \\
\text { contaminated }\end{array}$ & $\begin{array}{c}\text { No. of coagulase- } \\
\text { negative } \\
\text { Staphylococcus } \\
\text { (CONS) }\end{array}$ & $\begin{array}{c}\text { CONS + } \\
\text { Enterococcus } \\
\text { faecalis }\end{array}$ & $\begin{array}{l}\text { K. pneumoniae } \\
+ \text { CONS }\end{array}$ & $\begin{array}{l}\text { Efaecalis } \\
+ \text { Bacillus }\end{array}$ & $\begin{array}{c}\text { Escherichia } \\
\text { coli }+ \\
\text { CONS }\end{array}$ & $\begin{array}{l}\text { E. cloacae } \\
+ \text { E. faecalis }\end{array}$ \\
\hline D1 & 21 & $14(67)$ & $7(33)$ & 2 & 2 & 1 & - & & 1 \\
\hline $\mathrm{NNU}$ & 19 & $8(42)$ & $11(58)$ & 4 & 1 & 3 & 2 & 1 & - \\
\hline $\mathrm{C} 2$ & 10 & $6(60)$ & $4(40)$ & 1 & 1 & 1 & 1 & - & - \\
\hline $\mathrm{C} 3$ & 9 & $5(56)$ & $4(44)$ & 3 & 1 & - & - & - & - \\
\hline D2 & 17 & $12(71)$ & $5(30)$ & 1 & 2 & - & - & 2 & 1 \\
\hline D3 & 18 & $10(56)$ & $8(44)$ & 3 & 1 & 2 & 2 & - & - \\
\hline E4 & 22 & $13(59)$ & $9(41)$ & 2 & 4 & 1 & 1 & 1 & - \\
\hline Theatre & 10 & $6(60)$ & $4(40)$ & 3 & - & - & 1 & - & - \\
\hline Total & 126 & $74(59)$ & $74(41)$ & 19 & 12 & 8 & 7 & 4 & 2 \\
\hline
\end{tabular}

CONS $=$ coagulase-negative Staphylococcus 
Table 3: Distribution of organisms isolated from nasal swabs of medical staff.

\begin{tabular}{|c|c|c|c|c|c|c|}
\hline \multirow[t]{2}{*}{ Wards } & \multicolumn{6}{|c|}{ No. of specimens isolated from nasal swabs of medical staff } \\
\hline & $\begin{array}{c}\text { No. of Nasal } \\
\text { Swabs } \\
\text { sampled }\end{array}$ & $\begin{array}{c}\text { Staphylococcus } \\
\text { aureus }\end{array}$ & $\begin{array}{c}\text { S. aureus + } \\
\text { K. pneumoniae }\end{array}$ & $\begin{array}{c}\text { K. } \\
\text { pneumoniae }\end{array}$ & E. faecalis & CONS \\
\hline D1 & 21 & 11 & 2 & 1 & 4 & 3 \\
\hline NNU & 19 & 9 & - & - & 3 & 6 \\
\hline $\mathrm{C} 2$ & 10 & 3 & - & 1 & 2 & 4 \\
\hline $\mathrm{C} 3$ & 9 & 2 & - & - & 4 & 3 \\
\hline D2 & 17 & 10 & 2 & 1 & 2 & 2 \\
\hline D3 & 18 & 11 & - & 3 & 1 & 3 \\
\hline E4 & 22 & 13 & 1 & 4 & 1 & 3 \\
\hline Theatre & 10 & 2 & - & - & 3 & 5 \\
\hline Total & 126 & 61 & 5 & 10 & 20 & 29 \\
\hline
\end{tabular}

CONS = coagulase-negative Staphylococcus 


\section{K. FUSI NGWA et al. / Int. J. Biol. Chem. Sci. 4(5): 1529-1542, 2010}

Table 4: Effectiveness of decontamination of hospital equipment/surfaces over a 12 hour period.

\begin{tabular}{|c|c|c|c|c|c|c|c|c|c|c|c|c|c|c|c|c|c|c|c|c|c|}
\hline \multirow{3}{*}{$\begin{array}{l}\text { Equipment/ } \\
\text { surface }\end{array}$} & \multirow{3}{*}{$\begin{array}{l}\text { No } \\
\text { Screened }\end{array}$} & \multicolumn{20}{|c|}{$\%$ of surface with varying degrees of reduction in microbial flora over a period of 12 hours } \\
\hline & & \multicolumn{5}{|c|}{$\begin{array}{c}\text { \% five minutes after } \\
\text { decontamination }\end{array}$} & \multicolumn{5}{|c|}{$\%$ after 4 hours } & \multicolumn{3}{|c|}{$\%$ after 8 hours } & \multirow[b]{2}{*}{$1+$} & \multirow[b]{2}{*}{-} & \multirow[b]{2}{*}{ 4+ } & \multicolumn{4}{|c|}{$\%$ after 12 hours } \\
\hline & & 4+ & $3+$ & $2+$ & $1+$ & - & 4+ & $3+$ & $2+$ & $1+$ & - & $4+$ & $3+$ & $2+$ & & & & $3+$ & $2+$ & $1+$ & - \\
\hline Cot/ bed rail & 28 & 86 & 14 & - & - & - & - & 79 & 29 & - & - & - & 71 & 29 & - & - & - & 54 & 46 & - & - \\
\hline Weighing scale & 6 & 33 & 50 & 17 & - & - & - & 67 & 33 & - & - & - & 67 & 33 & - & - & - & 50 & 50 & - & - \\
\hline Incubator & 18 & 94 & 6 & - & - & - & 83 & 17 & - & - & - & - & 100 & - & - & - & - & 100 & - & - & - \\
\hline Oxygen tube & 10 & 80 & 20 & - & - & - & 80 & 20 & - & - & - & 70 & 30 & - & - & - & 30 & 50 & 20 & - & - \\
\hline Ambubags & 2 & 100 & - & - & - & - & 100 & - & - & - & - & $\begin{array}{l}10 \\
0\end{array}$ & - & - & - & - & 50 & 50 & - & - & - \\
\hline Laryngoscope & 3 & 100 & - & - & - & - & 33 & 67 & - & - & - & - & 100 & - & - & - & - & 100 & - & - & - \\
\hline Endoscope & 8 & 100 & - & - & - & - & - & 100 & - & - & - & - & 100 & - & - & - & - & 100 & - & - & - \\
\hline Suction catheter & 10 & 100 & - & - & - & - & 100 & - & - & - & - & 30 & 70 & - & - & - & - & 100 & - & - & - \\
\hline Endotracheal tubes & 4 & 100 & - & - & - & - & 100 & - & - & - & - & 25 & 75 & - & - & - & - & 100 & - & - & - \\
\hline Theatre light & 3 & - & 100 & - & - & - & - & 100 & - & - & - & - & 75 & - & - & - & - & 100 & - & - & - \\
\hline $\begin{array}{l}\text { Ceiling above } \\
\text { theatre light }\end{array}$ & 3 & - & 100 & - & - & - & - & 100 & - & - & - & - & 100 & - & - & - & - & 100 & - & - & - \\
\hline Face mask & 4 & 100 & - & - & - & - & - & 100 & - & - & - & - & 100 & - & - & - & - & 100 & - & - & - \\
\hline Dressing trolley top & 7 & - & 100 & - & - & - & - & 71 & 29 & - & - & - & 100 & - & - & - & - & 100 & - & - & - \\
\hline $\begin{array}{l}\text { Table surface/ area } \\
\text { for feed preparation }\end{array}$ & 9 & - & 22 & 33 & 44 & - & - & - & - & - & - & - & 43 & 57 & - & - & - & 29 & 71 & - & - \\
\hline
\end{tabular}


C. K. FUSI NGWA et al. / Int. J. Biol. Chem. Sci. 4(5): 1529-1542, 2010

\begin{tabular}{|c|c|c|c|c|c|c|c|c|c|c|c|c|c|c|c|c|c|c|c|c|c|}
\hline Locker top & 12 & - & 42 & 50 & 8 & - & - & 42 & 50 & 8 & 25 & - & 8 & 25 & 42 & 25 & - & 8 & 17 & 42 & 33 \\
\hline Wash basin & 30 & - & 73 & 23 & 3 & - & - & 73 & 23 & 3 & 3 & - & 67 & 20 & 10 & 33 & - & 67 & 20 & 10 & 3 \\
\hline Bed pan & 10 & - & 40 & 60 & - & - & - & 30 & 60 & 10 & 10 & - & 10 & 50 & 30 & 10 & - & - & 10 & 30 & 60 \\
\hline Toilet seat/ handle & 15 & - & 13 & 53 & 33 & - & - & 13 & 53 & 33 & 13 & - & 13 & 20 & 53 & 13 & - & - & 20 & 7 & 73 \\
\hline Sluice area & 7 & - & - & 29 & 71 & - & - & - & - & 29 & 86 & - & - & - & 14 & 86 & - & - & - & - & 10 \\
\hline Sink & 20 & - & 40 & 55 & 5 & - & - & 20 & 30 & 50 & 60 & - & 10 & 15 & 15 & 60 & - & - & - & 10 & 90 \\
\hline Tap & 20 & - & 40 & 55 & 5 & - & - & 20 & 30 & 50 & 60 & - & 10 & 10 & 20 & 60 & - & - & - & 40 & 60 \\
\hline Floor & 16 & - & 69 & 31 & - & - & - & - & 38 & 13 & 63 & - & - & 10 & 6 & 63 & - & - & 6 & 13 & 82 \\
\hline Wall & 16 & - & 81 & 19 & - & - & - & 81 & 19 & - & - & - & 81 & 81 & - & - & - & 81 & 19 & - & - \\
\hline Furniture surface & 16 & - & 63 & 38 & - & - & - & 63 & 38 & - & - & - & 44 & 44 & - & - & - & 44 & 56 & - & - \\
\hline
\end{tabular}




\section{DISCUSSION}

In this study, the hands of $59 \%$ of the staff examined were sterile after washing, ready to work on patients, while $41 \%$ had growth of different organisms. Personnel hand carriage of organisms has been postulated to mediate their transmission to patients (Doebbeling et al., 1992; Samore et al., 1996). The isolation of $E$. faecalis and other enteric bacteria from the hands of staff is a pointer to faecal contamination and probably also due to bad practices of picking the nose with fingers and sometimes using water to wash the anal region after stooling rather than toilet paper, hence effective hand washing using a standard technique is important. Hand washing after using a restroom or changing diapers or sanitary towels has been emphasized (Ayliffe et al., 1978; Vesley et al., 1992).

Hand hygiene is frequently referred to as the single most important measure for preventing the spread of infections and is extremely crucial in neonatal units as babies are handled a great deal (Federal Register notice, 1994). In paediatric wards at LUTH, the importance of hand washing before and after contact with patients, and after contact with a contaminated object is acknowledged (and motivated by posters), but factors such as understaffing and overcrowding sometimes militate against this norm. Although plain soaps have been shown to be adequate for routine hand washing for most ward procedures, antimicrobial hand washing products are advocated for hand washing when newborns, severely immunecompromised patients and patients in highrisk units are catered for and especially when hand washing has been shown to be inadequate in this study (Ayliffe et al, 1978; Lowbury, 1991; Chiba, 1994). An antimicrobial hand cleanser-Chlorhexidine $(40 \% \mathrm{w} / \mathrm{v})$, has been used with $98-100 \%$ efficacy (Casewell and Phillips, 1977; Doebbeling et al., 1992). Today antimicrobial hand rubs are in use in hospitals.
Risk of infection in childhood is quite great. Amongst caregivers could be nose and throat carriers of S. aureus and Streptococci or faecal carriers of diarrhoeal pathogens. The detection and treatment of carriers of potential pathogens are very important in infection control. S. aureus was isolated from the nasal swabs of $52 \%$ of medical staff. This result compared favorably with those of other workers (Stokes and Ridgway, 1980). The nose is a common carrier site which predisposes to heavy dissemination and high carrier rates among staff and even patients as well, and not excluding the air and surfaces. No wonder $S$. aureus is reported to be ubiquitous in hospital wards (Stokes and Ridgway, 1980). Streptococci were cultured from the throat swabs of 5\% of staff and $E$ coli from the stool of $8 \%$ of staff. Significant bacteriuria was noted in $11 \%$ of the staff. Treatment of carriers of pathogens particularly $S$. aureus resistant to methicillin is very essential because of its multi-resistance to commonly used drugs and to beta-lactams.

The problems of hospital infections include cross infections from the environment to the patients in the wards (Togashi, 1994). Environmental contamination facilitates pathogen transmission. A clean environment provides the required background to good standards of hygiene and asepsis, and maintains the confidence of patients and morale of staff (Maurer, 1985). Frequently used surfaces should be cleaned as many times as possible, and if ventilation standards are maintained, air should rarely be implicated in nosocomial infections. Periodic evaluation of the methods, thoroughness and the frequency of various decontamination processes will lead to improvement.

The modern hospital favors bacteria with special properties. Some bacteria are able to withstand or multiply in dilute antiseptics commonly applied to wounds and skin (Chiba, 1994). In this study, K. pneumoniae, $P$. mirabilis and some non-enteric bacilli were cultured from chlorhexidine (1.200) in some 
paediatric wards. Strains related to some of the types contaminating the antiseptics were also isolated from some infected patients. Bacterial contamination of antiseptics has been previously implicated in nosocomial infections at LUTH (Sogbetun et al., 1977; Anyiwo et al., 1982) and outbreaks elsewhere (Cheron et al., 1994). Periodic screening of these solutions will enable early detection of contaminants. Also, discriminate use of antiseptics, particularly the use of freshly prepared appropriate dilutions, plays an important role in the aetiology of nosocomial infections (Chiodo et al., 1989; D'Errico et al., 1989).

A low nurse to patient ratio is known to increase the risk of cross infections especially in intensive care units. It adds to the growing body of evidence demonstrating that adequate staffing is a key determinant and a prerequisite for adequate care and patient safety. More hospital nurses mean fewer infections. A low doctor to patient ratio is also evident of long queues waiting for long hours to see doctors (BioMed Central news, 2007).

This study identified discriminate decontamination policies in paediatric wards which need evaluation, lapses in hand washing practices by medical staff, carriers of potential pathogens among staff and inadequate supply of materials for patient care in paediatrics wards at LUTH, which are all predisposing factors of healthcare associated infections. Healthcare practitioners should pay prime attention to hospital hygiene, and personnel health and hygiene. Adequate staffing and supply of materials for patient care, continuous staff education on valid disinfection procedures, refresher courses to enhance the awareness of NI, continuous nosocomial infection surveillance to determine the success of control measures and to describe the epidemiology of emerging infections, and a sound laboratory are important in curtailing the risk of nosocomial infections.
In view of the fact that good health for children is an assurance for a new generation, children's forum (to better their general welfare and well being) is a priority for many governmental and non-governmental organizations. Health authorities should source for extra- funding from rich and philanthropic individuals, corporations and organizations to improve the general health scenario of children. This is critically important in this period of austerity. Epidemiologic studies will continue to play a vital role in the prevention and control of infections in hospitals.

\section{ACKNOWLEDGEMENTS}

The authors heartily thank all the staff of the Paediatric Department at the Lagos University Hospital who consented to take part in the study. Oxacillin E test strips and other identification kits were provided by the Africa Medical Department of Smithkline Beecham International, Nanterre Cedex, France, for which we are very grateful.

\section{REFERENCES}

Anyiwo CE, Coker AO, Daniel SO. 1982. Pseudomonas aeruginosa in postoperative wounds from chlorhexidine solutions. J. Hosp. Infect., 3: 189-191.

Ayliffe GAJ, Babb JR, Quoraishi AH. 1978. A test for hygienic hand disinfection. $J$. Clin. Path., 31: 923-924.

BioMed Central news, July 18, 2007.

Boyce JM, Opal SM, Chow JW, Zervos MJ, Potter- Bynoe G, Sherman CB, Romulo RLC, Fortna S, Medeiros AA. 1994. Outbreak of multidrug-resistant Enterococcus faecium with transferable van B class vancomycin resistance. $J$. Clin. Microbiol., 32: 1148-1153.

Casewell M, Phillips I. 1977. Hands as route of transmission for Klebsiella species. $\mathrm{Br}$. Med. J., 2: 1315-1317.

Cheron M, Abachin E, Guerot E, El-Bez M, Simonet M. 1994. Investigation of hospital-acquired infections due to 
Alcaligenes denitrificans sub-sp. xylosoxydans by DNA restriction fragment length polymorphism. J. Clin. Microbiol., 32(4): 1023-1026.

Chiba K. 1994. Aspects of disinfectants for the control of nosocomial infection. Hokkaido lga. ICU. Zasshi, 69(2): 182187.

Chiodo F, Falasca P, Finzi G. 1989. The role of antiseptics and disinfectants in the control of nosoconial infections. $J$. Chemother, 1(1): 25-27.

CLSI (Clinical and Laboratory Standards Institute) 2010: Performance standards for antimicrobial susceptibility testing. Twentieth Informational Supplement. M100-S20 vol. 30 No. 1.

D'Errico MM, Romano F, Grasso GM, Angelillo IF, Montanaro D. 1989. Evaluation of the effectiveness of disinfectants used in several Neopolitan hospitals. Ann. Ig., 1(3): 569-576.

Doebbeling BN, Stanley GL, Sheetz CT, Pfaller MA, Houston AK, Annis L, Li N, Wenzel RP. 1992. Corporative efficacy of alternative handwashing agents in reducing nosocomial infections in intensive care units. N. Engl. J. Med., 327(2): 88-93.

Dismuke WE. 1996. Emerging and reemerging infections. Am. J. Med., 100: 12-14.

Federal Register notice. 1994. Draft guidelines for isolation precautions in hospital, notice. Department of Health and Human services, Centers for Disease Control and Prevention.

French GL, Sharmon KP, Simmons N. 1996. Hospital outbreak of Klebsiella pneumoniae resistant to broad spectrum cephalosporins and $\beta$-lactam- $\beta$ lactamases inhibitor combination by hyper production of SHV-5- $\beta$ - lactamase. $J$. Clin. Microbiol., 34(2): 358-363.

Fujita K. 1994. Hospital infections in Paediatric patients. Hokkaido Igaku. Zasshi, 69(2): 160-165.
Gould DJ, Moralejo D, Drey N, Chudleigh JH. 2010. Interventions to improve hand hygiene compliance in patient care. Cochrane Database Syst. Rev., 8: 9.

Graham PL. 2010. Simple strategies to reduce healthcare-associated infections in the neonatal intensive care unit: line, tube and hand hygiene. Clin. Perinatol., 37(3): 645-53.

Helms CM, Massanari RM, Wenzel RP, Pfaller MA, Moyer NP, Hall N. 1988. The Legionella monitoring committee. Legionnaire disease associated with a hospital water system: a five years progress report on continuous hyper chlorination. JAMA, 259: 2423-2427.

Herwadt LA, Wenzel, RP. 1995. Dynamics of hospital acquired infections. In Manual of Clinical Microbiology ( $6^{\text {th }}$ edn), Murray PR, Baron EJ, Pfaller MA, Tenover FC, Yolken RH (eds). ASM Press: Washington DC; 169-181.

Hooper WL. 1971. The nature and extent of microbial contamination of pharmaceutical preparations in hospitals. Joint Symposium on Microbial Control, Pharmaceutical Society and Society of Cosmetic Chemists, Great Britain.

Jellife DB, Stanfield JP. 1982. Diseases of Children in the Subtropics and Tropics (3rd edn). ELBS; 1-9.

Kaltenthaler EC, Pinfold JV. 1995. Microbiology methods for assisting hand washing practice in hygiene behaviour studies. J. Trop. Med. Hyg., 98: 101-106.

Lowbury, EJL. 1991. Special problems in hospital antisepsis. In Principles and Practice of Disinfections, Sterilization and Preservation, Russel AD, Hugo WB, Ayliffe GAJ (eds). Blackwell Scientific Publication; 50-51.

Maki DJ. 1978. Control of colonization and transmission of pathogenic bacteria in the hospital. Ann. Intern. Med., 98: 777-780.

Maurer IM. 1985. Hospital Hygiene ( $3^{\text {rd }}$ edn). Wright PSG Bristol. 
Montgomery K, Ryan TJ, Krause A, Starkey C. 2010. Assessment of Athletic Health care facilty surfaces for MRSA in the secondary school setting. $J$ Environ Health, 72(6): 8-11.

Mulhausen PL, Harrell LJ, Weinberger M, Kochersberger GG, Feussner JR. 1996. Contrasting methicillin -resistant Staphylococcus aureus colonization in Veterans affairs and community nursing homes. Am. J. Med., 100: 24-27.

Muller MP, Detsky AS. 2010. Public reporting of hospital hand hygiene compliance- helpful or harmful? JAMA, 304(10): 1116-117.

Murray PR, Baron EJ, Pfaller MA, Tenover FC, Yolkens RH. 1995. Manual of Clinical Microbiology (6 ${ }^{\text {th }}$ edn). ASM Press: Washington DC.

National Committee for Clinical Laboratory Standards $\quad 1993$. Antimicrobial Susceptibility Testing. Methods for Dilution Antimicrobial Susceptibility Tests for Bacteria that grow aerobically . NCCLS DOCUMENT M7 - A3, Villanova, Pa.

Pechere JC. 1993. Microbiology of nosocomial infections. Bull. Acad. Natl. Med., 177(5): 701-718.

Rossini A, Balice MP, Ciotoli L, Guaglianone E, Donelli G, Salivia A. 2010. Healthcare workers with methicillin-resistant Staphylococcus aureus colonization and the use of contact precautions in daily activities with patients in an Italian Rehabilitation Hospital: The importance of hand hygiene training Infect. Control. Hosp. Epidemiol., 31(10): 1097-1098.
Samore MH, Venkataraman L, Degirolami PC, Arbeit RO, Karchmer, AW. 1996. Clinical and molecular epidermiology of sporadic and clustered cases of nosocomial Clostridium difficile diarrhea. Am. J. Med., 100: 32-40.

Sogbetun AO, Alausa KO, Onile BA, Montefiore D. 1977. Contamination of hospital antiseptics with gram-negative bacteria. Proceedings of the First National Symposium on Nosocomial infections, Lagos University Teaching Hospital, p. 72-77.

Stanforth B, Krause A, Starkey C, Ryan TJ. 2010. Prevalence of communityassociated methicillin-resistant Staphylococcus aureus in high school wrestling environments. J. Environ. Health, 72(9): 48-9.

Stokes EJ, Ridgway GL 1980. Hospital Epidemiology in Clinical Bacteriology ( $5^{\text {th }}$ edn). Edward Arnold; 301-338.

Togashi T 1994. Nosocomial infections and infection control committee. Hokkaido lgaku-Zasshi, 69(2): 157-60.

Vesley D, Norlien KG, Nelson B, Streifel AJ. 1993. Significant factors in the disinfection and sterilization of flexible endoscopes. Am. J. Infect. Control, 20(6): 291-300.

Wright C, Kominos SD, Yee RB. 1976. Enterobacteriaceae and Pseudomonas aeruginosa recovered from vegetable salads. Appl. Environ. Microbiol., 31: 453-454. 